\title{
HIV prevalence in Zimbabwe dropping like a stone
}

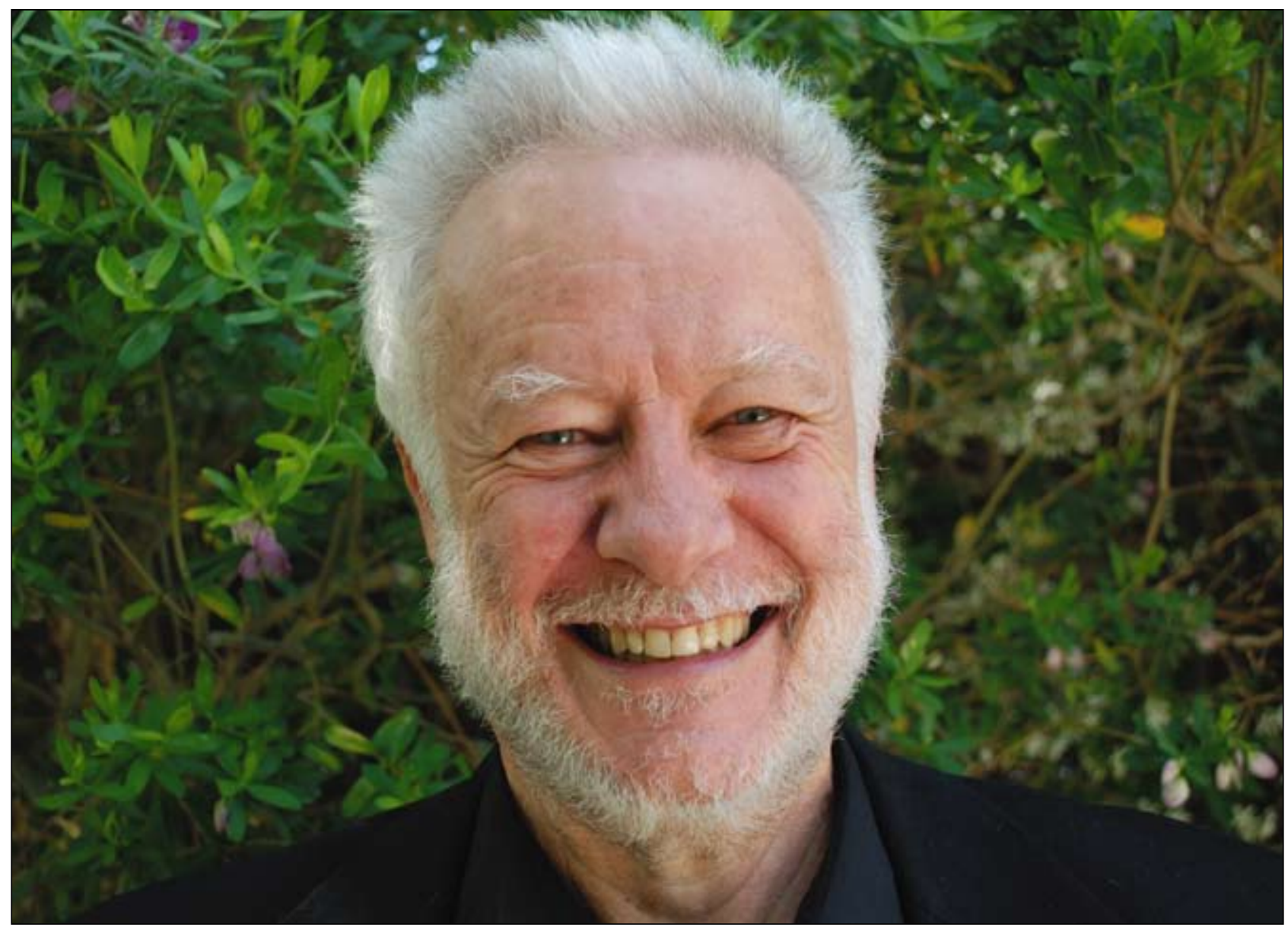

Brian Williams of the South African Centre for Epidemiological Modelling and Analysis.

Picture: Chris Bateman

HIV in Zimbabwe is disappearing like 'snow in the desert', in dramatic contrast to its neighbouring countries, mystifying epidemiologists, one of whom firmly believes the anomaly can be attributed to the country's relatively high level of education.

Brian Williams of the South African Centre for Epidemiological Modelling and Analysis (SACEMA), was speaking at the 2nd Consortium to Respond Effectively to the AIDS/TB epidemic (CREATE) in Cape Town during the first week of November.

He said reliable data showed that HIV/ AIDS prevalence in Zimbabwe had halved over the past 12 years, dropping from $30 \%$ in 1998 to $15 \%$ now. ${ }^{1}$ He suggested this could be put down to the country's population having benefited from a superior education that enabled them to 'absorb and respond to prevention messages.' 'My theory is that
Zimbabwe had the best-educated population in southern Africa - and prevention messages only work if people are able to understand, internalise and act on them, he added.

Williams said it was unlikely that the fall is due to the large portion of Zimbabwe's HIV-positive population that have migrated south in search of jobs and food, pointing to research showing that Zimbabweans either stayed home or returned home when their health deteriorated.

'My theory is that Zimbabwe had the best-educated population in southern Africa - and prevention messages only work if people are able to understand, internalise and act on them.'

\section{Zim 'infection-weight' in \\ SA low}

Izindaba also uncovered an integrated biological and behavioural survey of 2800 temporary farm labourers in the border provinces of Mpumalanga and Limpopo ${ }^{2}$ during fruit picking season late last year, which found the HIV 'infection weight' of Zimbabweans to be relatively low. While forming $17 \%$ of the itinerant labour force, their HIV prevalence was $28 \%$ compared with Mozambicans (14\% of the total but carrying $42 \%$ of the prevalence) and Swazis ( $8 \%$ of the total carrying $52 \%$ of the prevalence). South Africans accounted for $60 \%$ of the total seasonal labour force and had a $26 \%$ HIV prevalence.

This bolstered previous research by the International Organisation for Migration (IOM) pleading for HIV prevention programmes to target 'places of vulnerability', 
rather than individual groupings such as migrants.

\section{Target vulnerable 'hot spots' quickly and early}

Added IOM researcher Erin Tansey, 'Wherever there's a fluid social environment, such as mines, construction sites, trucking stops or seasonal farms, the usual social norms that curb sexual activities and constraints fall away and HIV becomes rampant. Just look at that Mozambican figure $(52 \%)$ - the HIV prevalence back home in Mozambique is 13\%!'

\section{Williams made a strong case to his colleagues in Cape Town for the introduction of ART immediately after testing positive as a powerful and long-term cost-effective prevention tool for both HIV and TB.}

Williams made a strong case to his colleagues in Cape Town for the introduction of ART immediately after testing positive as a powerful and long-term cost-effective prevention tool for both HIV and TB. He emphasised that it was crucial to establish the base line CD4 cell count among HIVnegative populations 'before even thinking of putting people on treatment regimens'.

$\mathrm{He}$ explained that this was because the impact of HIV on TB varied enormously among countries, proving to be greater where the initial incidence of TB was high and where the CD4 cell counts in HIV-negative people were high. Botswana's HIV-negative population, for example, had a far lower average CD4 cell count (about 640/ $\mu$ l) than South Africa (about $1200 / \mu l$ ), with dramatic implications for ART initiation.

'In Botswana, patients hit 500 within about a year of HIV infection while in South Africa it takes 4 - 5 years to get to 500 . So you need different (ART) initiation levels for different countries,' he added. He and his friend and research colleague, Chris Dye (of the World Health Organization), differed as to why the HIV incident ratios were different in Botswana, Zimbabwe and South Africa. Dye believed it to be a reflection of the degree of aggregation of HIV and TB in each country while he suspected it was because of the differences in the baseline CD4 cell counts. 'The trouble is we don't have the data to decide this conclusively,' he added. Williams said that for him it was a 'no brainer' to begin ART as soon as possible after people tested positive, but the reality was that governments were conservative in their approach.

'The question to ask researchers and politicians is this: If you were HIV positive would you delay or start treatment immediately?' he said. Williams said the very notion of using one $\mathrm{CD} 4$ cell count was ridiculous.

\section{'The question to ask researchers and politicians is this: If you were HIV positive would you delay or start treatment immediately?'}

\section{Test and initiate ART early to} save lives and money

'The HIV test is very cheap and the drugs cost about one dollar a day. While we will always need clinical support from doctors and nurses, much of the work of drug delivery, monitoring and support could be done by community workers. Not only would this make the whole system cheaper to deliver and more reliable, but it could be used to generate long-term jobs in some of the poorest communities. With the active engagement of people from the affected communities we can stop this pandemic in its tracks,' he added.

Trials for ART initiation upon testing HIV positive were running in New York and Washington. In San Francisco the public health authorities now recommend starting all patients on ART as soon as they are found to be HIV positive - unless there is a specific reason to defer therapy. A further benefit was the 'huge' efficacy of early ART initiation on tuberculosis co-infection (there is a $36 \%$ rise in the risk of TB for every drop of $100 \mathrm{CD} 4$ cells/ $\mu \mathrm{l})$.

\section{A further benefit was the 'huge' efficacy of early ART initiation on tuberculosis co-infection \\ (there is a $36 \%$ rise in the risk of TB for every drop of $100 \mathrm{CD} 4$ cells/ $\mu l)$.}

\section{Gold mine communities 'hot beds' of infection}

As if in affirmation of the 'places of vulnerability' conclusions in the IOM work of Tansey et al., Williams said he believes the reason nine sub-Saharan countries are the hardest hit by HIV globally is because of South Africa's gold mines. He said that when he arrived to run the 'Mothusimpilo' HIV prevention project in Carltonville and Khutsong Township in 1994 the prevalence among 15-year-old girls was zero. By 2001 when he left, the HIV prevalence among 25 -year-old girls was $75 \%$.

'You had tens of thousands of single male mine workers recruited from all over southern Africa with nothing but alcohol and sex for recreation. The 'hot spots' were right next to the mine shafts. Older women rented their shacks there to younger women sex workers who came from Botswana, Lesotho and Swaziland, he said.

Asked to respond to the cost barrier to ART initiation upon testing HIV positive, Williams said the cost had been calculated at about R6 500 per year per patient.

'So if you have six million HIV-positive citizens that would be about R39 billion annually... serious money, but once you stop transmission you save on hospitalisation, TB cases, opportunistic infections - and you save lives'. He added that 'while it is always tragic, the truth is that killing babies costs nothing, and killing old people like me costs nothing, but killing young, economically active adults is the worst thing you can do You've fed them, housed them, looked after them and educated them and just when they are in a position to pay back to society the investment society has made in them, you let them die!

'It will cost far more than R39 billion per annum to let them die. So ... in three to four years (with ART initiation at HIV-positive testing) you'd have effectively stopped transmission. Yes, it will still cost money to keep those infected on ART but you've stopped the incoming stream. You have to turn off the tap - that's the point!'

\section{Chris Bateman}

1. Lopman B, Gregson S. When did HIV incidence peak in Harare, Zimbabwe? Back-calculation from mortality statistics. Pub Lib Sci One 2008;3:e1711.

2. Durban-based Mark Colvin (Maromi Health Research Institute) commissioned by the IOM to conduct the survey on commercial farms in Limpopo and Mpumalanga where the IOM has HIV programmes running 